\title{
Análise situacional da qualidade de água nas zonas de uma instalação piscícola no Ceará - Brasil
}

Os índices de qualidade da água têm sido frequentemente estudados como ferramentas gerenciais para tomada de decisões relativas aos recursos hídricos. Nesta perspectiva, esta pesquisa teve como objetivo avaliar a variação dos índices de qualidade da água (IQA) e do estado trófico médio (IETm) nas áreas de influência de uma instalação de piscicultura familiar no reservatório Pereira de Miranda em Pentecoste, no Estado do Ceará. As coletas para as análises das variáveis físico-químicas e bacteriológicas foram realizadas em seis pontos de amostragens, nos períodos de estiagem e das chuvas. Por meio destas variáveis, o IQA e o IET foram estabelecidos para cada local, nos dois períodos de coleta. Os resultados classificaram a água como de boa qualidade em quase todos os pontos estudados. Isso sugere que a atividade de piscicultura praticada no açude não está comprometendo os múltiplos usos da água do reservatório. Por terem a facilidade de comunicação com o público não técnico através dos seus resultados, os índices podem ser replicados nas regiões com características semelhantes e cada vez melhorados nos estudos posteriores.

Palavras-chave: Qualidade da Água; Piscicultura; Índices de Qualidade da Água.

\section{Situational analysis of water quality in areas of an installation of pisciculture in Ceará - Brazil}

\begin{abstract}
The water quality indexes have often been studied, taking advantage of the use of your information as management tools for decision making regarding water resources. This study aimed to assess the variation in water quality indexes (WQI) and trophic state (mTSI) in the areas of influence of an installation to family pisciculture in the weir Pereira de Miranda in Pentecost, Ceará. Data were collected to analysis physicochemical and bacteriological for sampling at six sites in the dry and rainy season). Through these variables the WQI and STI were established for each site in the two collection periods. The water results were classified as good quality in almost all the points studied. This suggests that fish farming activity practiced in the were are not compromising the multiple uses of the reservoir water. Because they have the ease of communication with the non-technical public through their results, such indices can be replicated in the regions with similar and increasingly improved in features studies.
\end{abstract}

Keywords: Water Quality; Pisciculture; Water Quality Index.

Topic: Epidemiologia e Saúde Ambiental

Reviewed anonymously in the process of blind peer.

Geny Gil Sá (iD)

Universidade Federal do Ceará, Brasil

http://lattes.cnpq.br/1056814258621063

http://orcid.org/0000-0002-6452-3949

genygil@gmail.com

Diolande Ferreira Gomes (it)

Universidade Federal do Ceará, Brasil

http://lattes.cnpq.br/0048357648552119

http://orcid.org/0000-0002-6296-0977

dfreire68@gmail.com

George Satander Sá Freire

Universite de Nantes, França

http://lattes.cnpq.br/6803944360256138

freire@ufc.br

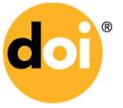

DOI: 10.6008/SPC2179-6858.2017.004.0005
Received: 06/07/2017

Approved: 08/10/2017

Reynaldo Amorim Marinho (ic)

Universidade Federal do Ceará, Brasil

http://lattes.cnpq.br/5782747621156489

http://orcid.org/0000-0001-5902-868X

marinhorey@gmail.com

Referencing this:

SÁ, G. G.; GOMES, D. F.; FREIRE, G. S. S.; MARINHO, R. A.. Análise situacional da qualidade de água nas zonas de uma instalação piscícola no Ceará - Brasil. Revista Ibero-Americana de Ciências Ambientais, v.8, n.4, p.55-65, 2017. DOI: http://doi.org/10.6008/SPC2179$\underline{6858.2017 .004 .0005}$ 


\section{INTRODUÇÃO}

Durante séculos a humanidade tratou a natureza como uma fonte inesgotável de bens de consumo que poderiam ser utilizados e explorados sem limites. Dentre esses recursos, encontra-se a água, um importante recurso natural indispensável para a sobrevivência não somente humana, mas de muitos outros seres no planeta. Para os seres humanos, a água tem influência direta sobre a saúde, o bem-estar humano e o desenvolvimento do ser humano. Enquanto no planeta desempenha um papel ecológico decisivo com respeito à existência e à qualidade de vida (SIMÕES et al., 2007).

A qualidade da água se determina em função dos processos de ocupação em uma bacia hidrográfica, sendo modificada por diversos fatores atuantes, como por exemplo, a implantação dos processos agropecuários, lançamento de efluentes domésticos, retirada de mata ciliar, etc. Os problemas de abastecimento hídrico no Brasil decorrem da combinação do crescimento exagerado das demandas localizadas associadas à degradação da qualidade das águas (OLIVEIRA, 2009).

À medida em que cresce a população que faz uso de um determinado recurso hídrico superficial (rio, reservatório, canal ou lagoa), há também um crescimento da demanda, contribuindo para aumentar a frequência com que acontecem períodos de escassez, e uma tendência por aumentar os impactos ambientais, contribuindo por deteriorar a qualidade da água. Simões et al. (2007) complementam que esse quadro é consequência do crescimento urbano desordenado com o desenvolvimento econômico, agrícola, industrial e tecnológico, os quais foram os principais responsáveis pela degradação da qualidade das águas de rios, lagos e reservatórios.

Nesta perspectiva, surgiram os índices de qualidade da água visando resumir as variáveis analisadas em um número que possibilitasse analisar a evolução da qualidade da água no tempo e no espaço, facilitando sua interpretação diante de extensas listas de variáveis ou indicadores, otimizando assim, o uso dessas informações como ferramentas gerenciais e na tomada de decisões relativas aos recursos hídricos (GASTALDINI et al., 1994, citado por OLIVEIRA, 2009).

Os corpos d'água no Brasil são classificados de acordo com a Resolução no 357/2005 do Conselho Nacional do Meio Ambiente (CONAMA, 2005), podendo apresentar 4 classes de qualidade baseados nos parâmetros indicadores de qualidade da água, assim quanto ao uso a que se destinam. Neste trabalho foi usado o critério de classificação para classe 2 , tendo em conta que esta classe de qualidade se destina à aquicultura e à atividades de pesca e conforme o Artigo 42, da resolução acima mencionada, enquanto não aprovados os respectivos enquadramentos, as águas doces serão consideradas classe 2 .

De acordo com a Agência Nacional de Águas (ANA, 2009), o IQA foi criado em 1970, nos Estados Unidos, pela National Sanitation Foundation (NSF), tendo São Paulo como primeiro estado a adotá-lo, em 1975, e hoje aceito nacionalmente como principal indicador de qualidade das águas utilizado no país (SÃO PAULO, 2007).

Na região Nordeste do Brasil a questão da eutrofização dos açudes é preocupante. Os corpos hídricos ficam submetidos à intensa evaporação e escassas precipitações, concentrando sais e compostos de fósforo e nitrogênio, algo que intensifica o crescimento de microalgas e cianobactérias (LAMPARELI, 2004) e por sua 
vez a eutrofização. Para amenizar essa problemática, o IET tem como finalidade classificar corpos d'água em diferentes graus ou níveis de trofia, ou seja, avalia a qualidade da água quanto ao enriquecimento por nutrientes e seu efeito relacionado ao crescimento excessivo das algas ou ao aumento da infestação de macrófitas aquáticas (SÃO PAULO, 2006). Este índice sofreu várias adaptações ao longo do tempo, sendo atualmente calculado em função dos valores médios de fósforo total e clorofila $a$, e sendo expresso para rios e reservatórios. Conforme a classificação proposta por Toledo Junior (1990), os valores de IET médio podem variar de oligotrófico $\left(\mathrm{IET}_{\mathrm{m}} \leq 44\right)$ a hipertrófico $(\mathrm{IETm}>74)$.

Esta investigação avaliou a qualidade da água nas áreas de influência de uma instalação de piscicultura no reservatório Pereira de Miranda, localizado no município de Pentecoste, no estado do Ceará, por meio da aplicação dos índices de qualidade da água (IQA) e do estado trófico (IET). A pesquisa revestese de fundamental importância para a região, na medida em que os índices são fundamentais nos processos decisórios de políticas públicas de qualidade da água nos açudes públicos e no acompanhamento dos seus efeitos.

\section{METODOLOGIA}

O estudo foi realizado no reservatório Pereira de Miranda, construído sobre os leitos dos rios Canindé e Capitão Mor, no município de Pentecoste, no Estado do Ceará, conforme ilustrado na figura 1. É o maior açude da bacia hidrográfica do sistema Curu, com capacidade de acumulação de $395.638 .000 \mathrm{~m}^{3}$ e suas águas têm como finalidades o abastecimento de água, a regulação do Rio Curu, a irrigação das terras a jusante, a geração de energia elétrica, a piscicultura e o aproveitamento das culturas à montante, influenciando diretamente o bem-estar humano e ecossistêmico.

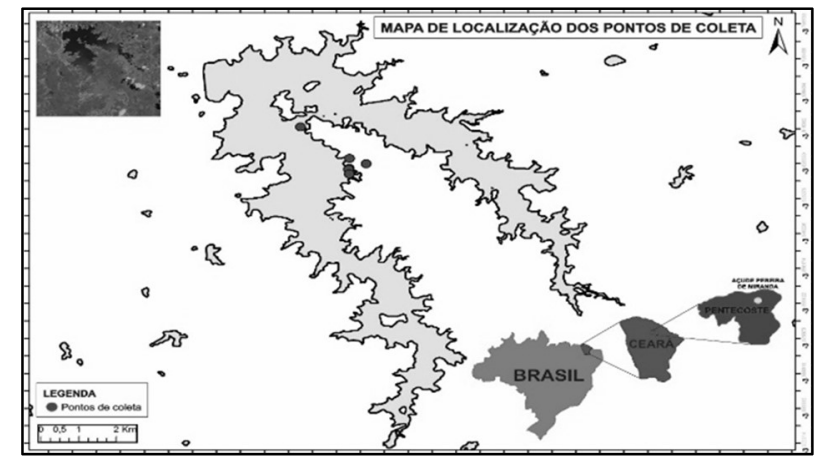

Figura 1: Mapa de localização da área de estudo e de distribuição dos pontos de coleta.

Os dados referentes aos parâmetros físico-químicos e bacteriólogicos, que compõem os índices de qualidade da água e do estado trófico, foram coletados no período de estiagem e no período chuvoso, com um total de seis pontos de amostragens. Das 35 variáveis indicadoras de qualidade de água, 9 (nove) foram selecionadas por serem mais relevantes para o tipo de uso desse recurso hídrico - abastecimento público (Tabela 1). Desse modo, foram trabalhadas as seguintes variáveis: 1) oxigênio dissolvido; 2) pH; 3) temperatura; 4) demanda bioquímica de oxigênio; 5) fósforo total; 6) nitrogênio total; 7) sólidos totais; 8) coliformes termotolerantes; e, 9) turbidez (CETESB, 2007). O resultado determina a qualidade das águas, que pode variar de péssima $(0<\mathrm{IQA} \leq 20)$ a ótima $(80<\mathrm{IQA} \leq 100)$ qualidade. 
Tabela 1: Variáveis analisadas no IQA e respectivas metodologias de análises.

\begin{tabular}{|l|l|}
\hline Parâmetros & Métodos analíticos \\
\hline $\mathrm{pH}$ & Peagâmetro \\
\hline Oxigênio dissolvido & Método iodométrico de Winkler modificado pela azida \\
\hline $\begin{array}{l}\text { Demanda bioquímica de oxigênio } \\
\left(\mathrm{DBO}_{5}\right)\end{array}$ & $\begin{array}{l}\text { Incubação }\left(20^{\circ} \mathrm{C}, 5 \text { dias }\right) \text {, com leituras de oxigênio dissolvido obtido pelo método } \\
\text { iodométrico. }\end{array}$ \\
\hline Fósforo total (PT) & Oxidação alcalina com persulfato de sódio seguida de método do ácido arcórbico \\
\hline Nitrogênio total & $\begin{array}{l}\text { Oxidação alcalina com persulfato de sódio seguida de método da coluna redutora de } \\
\text { cádmio }\end{array}$ \\
\hline Turbidez & Turbidimêtrico com turbidímetro Thermo Orion modelo AD 2010 \\
\hline Sólidos dissolvidos totais & Gravimétrico a $100^{\circ} \mathrm{C}$ \\
\hline Clorofila $a$ & Filtragem e espectrofotometria \\
\hline Coliformes termotolerantes & Tubos múltiplos \\
\hline Temperatura & Sonda \\
\hline
\end{tabular}

Fonte: APHA, 2005.

As análises foram realizadas no Laboratório de Geoquímica Ambiental do Departamento de Geologia da Universidade Federal do Ceará, cujos procedimentos metodológicos foram seguidos de acordo com o Standard Methods (APHA, 2005), Grasshoff et al. (1983) e CETESB (2006). O cálculo do IQA foi efetuado de acordo com a fórmula descrita (CETESB, 2007; ANA, 2009): IQA $=\prod_{i=1}^{n} \mathrm{qi}^{\mathrm{wi}}$, onde, IQA: Índice de Qualidade da Água, um número entre 0 e 100; qi: qualidade individual (sub-índice) do i-ésimo parâmetro, um número entre 0 e 100, obtido em função de sua concentração ou medida; wi: peso correspondente ao i-ésimo parâmetro, um número entre 0 e 1, atribuído em função da sua importância para a conformação geral de qualidade; e n: número de parâmetros que entram no cálculo do IQA.

O IET tem como finalidade classificar corpos d'água em diferentes graus de trofia, ou seja, avalia a qualidade da água quanto ao enriquecimento por nutrientes e seu efeito relacionado ao crescimento excessivo das algas ou ao aumento da infestação de macrófitas aquáticas. Este índice sofreu várias adaptações ao longo do tempo, sendo atualmente calculado em função dos valores de fósforo total e clorofila a, e sendo expresso para rios e reservatórios (CETESB, 2006; TOLEDO JUNIOR, 1990). O IET é obtido por meio dos valores de fósforo total - IET $T_{\text {ptot }}$ e da clorofila $a$ - cLa, segundo as equações para reservatórios de Lamparelli (2004), apresentadas a seguir: $P_{\text {tot }}=10$ x [6-(1,77-0,42x(In PT)/In 2)]; e $C L_{a}=10$ x [6-(0,92-0,34x(In $\mathrm{CL}) / \mathrm{In} 2)$ ], onde $\mathrm{P}_{\text {tot: }}$ : Fósforo total; $C L_{a}$ : Clorofila a; e Ln: logaritmo neperiano.

Uma vez disponíveis os dados de ambas as variáveis (fósforo total e clorofila a), em todos os pontos analisados, o índice de estado trófico médio (IET $\mathrm{m}$ ) foi calculado a partir da média aritmética simples dos índices relativos ao fósforo total e a clorofila $a$, conforme a expressão $\mathrm{IET}_{\mathrm{m}}=\left[\left(P T_{\text {tot }}\right)+\left(C L_{a}\right)\right] / 2$, possuindo a mesma legenda.

\section{RESULTADOS}

Todos os valores da análise físico-química e bacteriológica estão dispostos na Tabela 2. Os valores dos parâmetros físico-químicos e bacteriológicos das águas superficiais nos pontos estudados do açude Pereira de Miranda, foram utilizados para o cálculo do IQA, sendo realizada uma comparação dos resultados obtidos no cálculo com a classificação da qualidade das águas recomendada pela CETESB. Analisando os valores do IQA para os dois períodos em que foram feitas as amostragens, verificou-se que as águas de quase 
todos os pontos estudados se situam na categoria de classificação boa com exceção do ponto-1 do período de estiagem destacado na categoria de classificação ótima (Tabela 3).

Tabela 2: Resultados das análises de água em diferentes pontos de amostragem no açude Pereira de Miranda para o cálculo do IQA e IET nos períodos de estiagem e chuva.

\begin{tabular}{|c|c|c|c|c|c|c|c|c|c|c|c|c|c|c|}
\hline \multirow[b]{2}{*}{ Variáveis } & \multirow{2}{*}{$\begin{array}{c}\text { Resolução } \\
\text { (n-357/2005) classe } \\
2\end{array}$} & \multirow[b]{2}{*}{ Unidades } & \multicolumn{6}{|c|}{ Estiagem } & \multicolumn{6}{|c|}{ Chuva } \\
\hline & & & P1 & P2 & P3 & P4 & P5 & P6 & P1 & P2 & P3 & P4 & P5 & P6 \\
\hline $\begin{array}{c}\text { Coliformes } \\
\text { termotolerantes }\end{array}$ & 1000 & $\begin{array}{l}\text { (NMP/ } \\
100 \mathrm{~mL})\end{array}$ & aus & aus & aus & aus & aus & aus & aus & aus & aus & aus & aus & aus \\
\hline $\mathrm{pH}$ & $6.9-9.0$ & - & 7.9 & 7.9 & 8.0 & 8.0 & 7.9 & 8.0 & 8.1 & 8.6 & 8.4 & 8.7 & 8.4 & 8.3 \\
\hline $\mathrm{DBO}_{5}$ & $\leq 5$ & $\mathrm{mg} \mathrm{L}^{-1}$ & 2.8 & 3.0 & 2.1 & 1.4 & 1.6 & 1.4 & 3.5 & 3.0 & 2.9 & 3.2 & 3.0 & 1.4 \\
\hline Nitrogênio total & 2.18 & $\mathrm{mg} \mathrm{L}^{-1}$ & 1.2 & 0.8 & 1.0 & 0.9 & 0.30 & 0.9 & 1.5 & 1.1 & 1.1 & 1.1 & 1.1 & 1.0 \\
\hline Fósforo total & $\leq 0.05$ & $\mu \mathrm{g} \mathrm{L}^{-1}$ & 0.1 & 0.1 & 0.1 & 0.1 & 0.16 & 0.1 & 0.1 & 0.1 & 0.2 & 0.1 & 0.1 & 0.1 \\
\hline Turbidez & $\leq 100$ & UNT & 15.3 & 16.1 & 16.3 & 16 & 17 & 11 & 12 & 17 & 19 & 18 & 17 & 16 \\
\hline Sólidos totais & - & - & 5.6 & 5.4 & 11.6 & 0.8 & 6.1 & 4.4 & 2.4 & 3.1 & 4.5 & 18.2 & 14 & 2.0 \\
\hline Oxigênio dissolvido & $\geq 5$ & $\mathrm{mg} \mathrm{L}^{-1}$ & 4.9 & 4.9 & 5.4 & 4.0 & 6.2 & 4.5 & 6.0 & 7.5 & 6.6 & 7.0 & 6.7 & 6.0 \\
\hline Clorofila $a$ & 30 & $\mu \mathrm{g} \mathrm{L}^{-1}$ & 6.5 & 0.6 & 5.4 & 12.7 & 5.2 & 11.6 & 19.0 & 14.7 & 7.7 & 18.2 & 5.9 & 10.2 \\
\hline Temperatura & - & $\stackrel{\circ}{ } \mathrm{C}$ & 30 & 28.4 & 26.5 & 27.2 & 31 & 30.9 & 29.6 & 27.5 & 30.5 & 31.4 & 29.0 & 28.1 \\
\hline
\end{tabular}

Legenda: aus: ausência.

Tabela 3: Valores do IQA estabelecidos pelos cálculos para os pontos estudados no decorrer da pesquisa.

\begin{tabular}{|c|c|c|c|c|}
\hline \multirow{2}{*}{ Pontos } & \multicolumn{2}{|c|}{ Estiagem } & \multicolumn{2}{c|}{ Chuva } \\
\cline { 2 - 5 } & IQA & Classificação & IQA & Classificação \\
\hline 1 & 81.78 & Ótima & 74.78 & Boa \\
\hline 2 & 75.93 & Boa & 74.48 & Boa \\
\hline 3 & 78.83 & Boa & 74.66 & Boa \\
\hline 4 & 72.91 & Boa & 68.98 & Boa \\
\hline 5 & 76.43 & Boa & 66.25 & Boa \\
\hline 6 & 76.93 & Boa & 72.50 & Boa \\
\hline Índice médio & 77.14 & Boa & & Boa \\
\hline
\end{tabular}

Quanto aos valores do IET $m$, propostos na tabela 4, constatou-se que no período de estiagem as águas dos pontos (P4 e P6) se classificaram mesotrófico, o que significa que há uma produtividade intermediária, com possíveis implicações sobre a qualidade da água, porém em níveis aceitáveis, enquanto que os demais (P1, P2, P3 e P5) situaram-se dentro do grau oligotrófico, ou seja, existem baixas concentrações de nutrientes e pouca produtividade, logo, a qualidade da água não ocasiona prejuízo aos usos múltiplos do recurso no manancial. Já no período chuvoso, verificou-se, segundo os resultados obtidos nos cálculos que as águas de todos os pontos analisados se qualificaram como mesotrófico.

Tabela 4: Valores do IET $m$ estabelecidos pelos cálculos para os pontos estudados no decorrer da pesquisa.

\begin{tabular}{|c|c|c|c|c|}
\hline \multirow{2}{*}{ Pontos } & \multicolumn{2}{|c|}{ Estiagem } & \multicolumn{2}{|c|}{ Chuva } \\
\cline { 2 - 4 } & $\mathrm{IET}_{\mathrm{m}}$ & Grau de trofia & $\mathrm{IET}$ & Grau de trofia \\
\hline 1 & 42.55 & Oligotrófico & 49.13 & Mesotrófico \\
\hline 2 & 37.50 & Oligotrófico & 51.60 & Mesotrófico \\
\hline 3 & 42.50 & Oligotrófico & 49.88 & Mesotrófico \\
\hline 4 & 44.70 & Mesotrófico & 50.86 & Mesotrófico \\
\hline 5 & 43.50 & Oligotrófico & 52.23 & Mesotrófico \\
\hline 6 & 44.75 & Mesotrófico & 50.35 & Mesotrófico \\
\hline Índice médio & 42.58 & Oligotrófico & 50.67 & Mesotrófico \\
\hline
\end{tabular}




\section{DISCUSSÃO}

Ph da água

Os valores de $\mathrm{pH}$ variaram entre 7.9 e 8.7 em todos os períodos amostrados, apresentando-se dentro da neutralidade e atendendo aos padrões de qualidade da água de classe 2 da Resolução CONAMA no357/2005 que estabelece o limite de 6.0 a 9.0 para o pH. Os ecossistemas com elevados valores de pH, segundo Esteves (1998), são encontrados, geralmente, em regiões com balanço hídrico negativo, isto é, quando a precipitação é menor do que a evaporação. No Brasil os açudes nordestinos, especialmente durante o período de estiagem, apresentam valores de $\mathrm{pH}$ geralmente superiores a 8.0. No açude estudado foi observada uma nítida diferença sazonal nos valores de $\mathrm{pH}$, mas um leve aumento no período de chuvas, indicando que estas foram insuficientes para causar mudanças.

\section{Oxigênio dissolvido}

Para o oxigênio dissolvido (OD) o valor máximo obtido nas análises de água foi de $7.5 \mathrm{mg} / \mathrm{L}^{-1}$ fato ocorrido no período das chuvas no ponto de coleta 2, e o valor mínimo de $4.0 \mathrm{mg} / \mathrm{L}^{-1}$ ocorreu no período de estiagem no ponto 4. Em alguns pontos amostrados, na estiagem, os valores de OD não apresentaram concordância com o limite estabelecido pela resolução CONAMA no357/2005 que define uma faixa de $\geq$ $5 \mathrm{mg} / \mathrm{L}^{-1}$. Porém, para a atividade de piscicultura a concentração mínima de oxigênio recomendada deve ser $\geq 4 \mathrm{mg} / \mathrm{L}^{-1}$ (ARANA, 1999).

\section{Demanda bioquímica de oxigênio $\left(\mathrm{DBO}_{5}\right)$}

A demanda bioquímica de oxigênio, ou seja, quantidade de oxigênio consumido durante 5 dias $\left(\mathrm{DBO}_{5}\right)$, apresentou variações com valores mínimos de $1.4 \mathrm{mg} / \mathrm{L}^{-1} \mathrm{O}_{2}$ tanto no período de estiagem (pontos 4 e 6) como nas chuvas (ponto 6), respectivamente. O máximo valor obtido desse parâmetro foi de $3.5 \mathrm{mg} / \mathrm{L}^{-}$ ${ }^{1} \mathrm{O}_{2}$, corroborando estar dentro dos limites estabelecidos pela Resolução do órgão ambiental responsável ( $\leq$ $\left.5 \mathrm{mg} / \mathrm{L}^{-1}\right)$.

Cabe acrescentar que valores elevados de DBO podem reduzir os níveis de oxigênio na água. Águas com níveis de DBO inferiores a $4 \mathrm{mg} / \mathrm{L}^{-1} \mathrm{O}_{2}$ são razoavelmente limpas, já com $10 \mathrm{mg} / \mathrm{L}^{-1} \mathrm{O}_{2}$ são consideradas poluídas, uma vez que elas contém grandes quantidades de matéria orgânica (MCNEELY, 1979). Enquanto a redução da matéria orgânica, segundo Esteves (1998), é atribuída à sedimentação e/ ou precipitação ou decomposição da mesma.

\section{Fósforo total (PT)}

Quanto ao fósforo total, nenhum dos valores encontrados nos pontos estudados, atendeu ao padrão estabelecido aos teores de fósforo total pela Resolução CONAMA no357/05 $\left(\leq 0.05 \mu \mathrm{g} / \mathrm{L}^{-1}\right)$, contudo, não foram verificadas fontes pontuais de poluição antrópica como os esgotos domésticos ricos em compostos superfosfatados presentes em detergentes e matéria fecal. Os valores mais altos do fósforo foram 
encontrados nas zonas de influência da atividade de piscicultura e no ponto de encontro das águas do rio Canindé e capitão Mor, como por exemplo, nos pontos P-3 (0.20) e P-6 (0.17). Logo, não se descarta a possibilidade de oscilações do teor de fósforo estarem sendo ocasionadas pelo fornecimento de ração aos peixes cultivados, uma vez que ao longo do açude verificam-se outras instalações de piscicultura.

A determinação das concentrações de fósforo na água e sedimentos é uma etapa fundamental para o monitoramento e controle da eutrofização artificial, bem como para o conhecimento dos padrões de ciclagem do fósforo em ambientes aquáticos (ESTEVES, 2011). Wetzel (1993) defende que a variabilidade no comportamento do fósforo na coluna d'água está relacionada ao seu próprio ciclo biogeoquímico que, por sua vez, é fortemente influenciado por fatores ambientais como pluviosidade, temperatura, $\mathrm{pH}$ e atividades biológicas.

Segundo Esteves (1998), o fósforo é um dos parâmetros mais importantes para a qualidade das águas, devido sua participação no metabolismo dos seres vivos, constituindo num dos principais fatores limitantes para a produtividade primária em ecossistemas aquáticos continentais. A desconformidade dos resultados do fósforo com o estabelecido pela Resolução Conama pode também estar relacionada às características naturais do ambiente, já que as fontes naturais desse nutriente são as próprias rochas da bacia de drenagem onde a sua liberação ocorre a partir da desagregação da forma cristalina dos minerais primários das rochas, dentre estes, o mais importante é a apatita, mineral que contém 95\% do fósforo existente na crosta terrestre (SMIL, 2000). Portanto, apenas os monitoramentos de longo prazo da qualidade da água em pontos à montante e à jusante das atividades de piscicultura serão eficientes para o esclarecimento da variabilidade no comportamento do fósforo.

\section{Nitrogênio total (NT)}

No período de estiagem os valores de nitrogênio total variaram de 0.30 a $1.21 \mathrm{mg} / \mathrm{L}^{-1}$, já no período chuvoso este parâmetro variou de 1.05 a $1.56 \mathrm{mg} / \mathrm{L}^{-1}$, valores mínimos e máximos, respectivamente. Nota-se um ligeiro aumento do valor medido de nitrogênio total no período das chuvas, fato que talvez esteja relacionado com o aporte de matéria orgânica carreada pela chuva para o corpo hídrico.

Contudo, os valores medidos de nitrogênio total atendem à Resolução Conama $\left(2.18 \mathrm{mg} / \mathrm{L}^{-1}\right)$, indicando boa qualidade da água em relação a este parâmetro. Esteves (2011) explica que uma das principais fontes de nitrogênio para os ecossistemas aquáticos continentais são as chuvas, aporte de material orgânico e inorgânico a partir de ecossistemas adjacentes, a fixação biológica de nitrogênio (processo de transformação de $\mathrm{N}_{2}$ em $\mathrm{N}$ biológico), além do aporte do de efluentes domésticos e industriais não tratados ou parcialmente tratados nos corpos d'água.

\section{Turbidez}

A turbidez da água variou de 11 a 19UNT, valores inferiores ao limite aceitável, ou seja, em todos os pontos amostrados, os valores de turbidez obedeceram ao padrão estabelecido pela legislação vigente, estando abaixo de 100UNT. Barros et al. (2001) encontrou valores de turbidez na sub-bacia Córrego André, 
MS, variando de menor (4.3UNT) ao maior valor (83.2UNT), porém dentro do limite estabelecido em relação ao padrão de qualidade. A turbidez é um dos parâmetros mais importante nos estudos de qualidade da água devido à grande adsorção de substâncias tóxicas, tanto orgânicas como inorgânicas, às partículas coloidais e em suspensão. De acordo com Vilaginès (2003), em média 90\% das substâncias tóxicas são adsorvidas por estas partículas.

\section{Sólido total (ST)}

O sólido total é a matéria que permanece após a evaporação da amostra de água durante um determinado tempo e temperatura. Esses materiais aumentam a turbidez e diminuem a transparência da água e ao longo do tempo causam assoreamento. Os resultados de sólidos totais oscilaram de 0.8 a $11.6 \mathrm{mg} / \mathrm{L}^{-}$ ${ }^{1}$ no período de estiagem, e de 2.0 a $18.2 \mathrm{mg} / \mathrm{L}^{-1}$ no período chuvoso. Estes resultados explicam os baixos valores de turbidez encontrados em todos os pontos amostrados. Os valores para sólidos totais devem ser inferiores a $30 \mathrm{mg} / \mathrm{L}^{-1}$, para o bom desenvolvimento de peixes em tanques-rede. Moraes (2005) realizou no mesmo açude um estudo sobre análise dos aspectos ambientais e descobriu maiores concentrações de sólidos no período de estiagem $\left(2.0\right.$ e $\left.43.0 \mathrm{mg} / \mathrm{L}^{-1}\right)$ que no período chuvoso, com variações entre $4.4 \mathrm{e}$ $9.6 \mathrm{mg} / \mathrm{L}^{-1}$.

\section{Clorofila $a$}

Os valores encontrados para clorofila $a$ oscilaram bastante durante o período investigado, resultando em valores mínimo e máximo iguais a 0.6 e $18.2 \mu \mathrm{g} \mathrm{L}^{-1}$ no ponto 2 (período de estiagem) e no ponto 4 (período de chuvas). A concentração desse pigmento é comumente utilizada em estudos limnológicos para estimar a biomassa fitoplanctônica de um corpo hídrico e o seu emprego nestes estudos se refere ao papel como um dos principais responsáveis pela fotossíntese, sendo, portanto, um valioso indicador do estado trófico de um ecossistema aquático.

Oliveira (2009) realizou um estudo de qualidade ambiental deste mesmo reservatório por meio de índice do estado trófico, onde encontrou uma grande variação de clorofila $a$ durante a série temporal proposta, oscilando de 0.7 a $48.5 \mu \mathrm{g} / \mathrm{L}^{-1}$. O autor concluiu que a evolução da produtividade primária pode ser uma resposta da comunidade fitoplanctônica com a proximidade da parede do açude, que, por acumular as águas drenadas dos rios, aumenta o tempo de residência e por consequência o tempo de assimilação desses nutrientes disponíveis na água.

\section{Coliformes termotolerantes}

Os coliformes termotolerantes são indicadores de contaminação de origem fecal. Águas com níveis elevados deste indicador apresentam riscos à saúde humana e ao meio aquático, pois sugerem a presença de patógenos (CETESB, 2004). De acordo com a resolução CONAMA no 357/2005 as águas dos reservatórios não deverão exceder o limite de até $1.000 \mathrm{NMP}$ de coliformes termotolerantes por $100 \mathrm{~mL}$ em $80 \%$ ou mais de pelo menos seis amostras de água. 
No resultado apresentado na tabela 2 não foi detectado o crescimento de nenhuma célula nos pontos analisados, não revelando nenhum risco ambiental. O não recebimento de efluentes industriais podem ter contribuído para este resultado. Portanto, os índices de coliformes obtidos atenderam os limites dos padrões estabelecidos pela legislação vigente.

\section{Temperatura}

Em relação à temperatura da água, no período de estiagem os valores deste parâmetro variaram de 27.23 a $31.0^{\circ} \mathrm{C}$. Já no período chuvoso houve uma variação de 27.46 a $31.57^{\circ} \mathrm{C}$. A temperatura influencia vários parâmetros físico-químicos da água, pois todos os corpos d'água apresentam variações de temperatura ao longo do dia e das estações do ano. Valores semelhantes a estes também foram encontrados por Moraes (2005) no seu estudo sobre análises dos aspectos ambientais do mesmo açude.

Gurgel et al. (1999) verificou na mesma área de estudo a circulação da água da superfície ao fundo durante todo o ano, nunca se observando qualquer momento de estratificação térmica. A elevada temperatura do ar e a intensa radiação solar durante todo o ano são responsáveis pelas elevadas temperaturas da água. As pequenas variações de temperatura, observado por Gurgel et al. (1999) entre as três camadas (superfície, meio e fundo) podem estar relacionadas a esses fatores e a ação dos ventos.

\section{CONCLUSÕES}

Os parâmetros analisados atenderam, parcialmente, aos padrões dos valores estabelecidos pela resolução CONAMA no357/2005 para água classe 2. As variações apresentadas não foram significativas a ponto de refletirem nos resultados finais. $O$ índice de qualidade da água (IQA), observado nos seis pontos estudados, revela que a água teve classificação entre 'ótima' (apenas 1 ponto) e 'boa', e isso pode indicar que a atividade de piscicultura não influenciou diretamente na qualidade da água nos períodos em que foi realizado o estudo e consequentemente os usos previstos para água do açude.

$\mathrm{O}$ índice de estado trófico médio ( $\mathrm{IET}_{\mathrm{m}}$ ), observado nos seis pontos amostrados, foi classificado, de acordo com o grau de estado de trofia em 'oligotrófico' (baixa produtividade de nutrientes e consequentemente, baixo prejuízo aos usos múltiplos nos pontos amostrados) e 'mesotrófico', indicando que existe uma ocorrência de produtividade intermediária de nutrientes nos pontos em questão, porém em níveis aceitáveis. Ressalta-se que essa é uma condição comum nas águas continentais do estado do Ceará, com ou sem a prática de piscicultura.

Além das técnicas citadas neste trabalho para indicar as condições de qualidade da água nos sistemas de criação de peixes, respostas satisfatórias podem ser obtidas através da aplicação de práticas adequadas de manejo. Devem-se levar em consideração diversos estudos que abordam a importância de conhecer a dinâmica de funcionamento do sistema de criação de peixes através de uma visão integrada de meio ambiente e manejo ecológico.

Embora Valenti (2008) demonstra, através de indicadores, que a aquicultura brasileira não é sustentável, os efeitos ambientais podem ser minimizados, sendo necessário averiguar a capacidade de 
suporte das estruturas utilizadas para produção de peixes, monitorando, controlando e aplicando técnicas de manejo compatíveis ao tipo de produção e visando estabilidade das condições ambientais.

Assim, concluiu-se que a atividade de piscicultura praticada no açude não está comprometendo os múltiplos usos da água do reservatório. Por terem a facilidade de comunicação com o público não-técnico através dos seus resultados, tais índices podem ser replicados nas regiões com características semelhantes e cada vez melhorados nos estudos posteriores, com vista ao equilíbrio entre as necessidades e as limitações do piscicultor com o ecossistema aquático, estabelecendo os princípios do uso sustentável dos reservatórios públicos.

\section{REFERÊNCIAS}

AMANCIO, A. L. L.; FARIAS, W. R. L.; SILVA NETO, A. R.. Balanço de nutrientes da água do açude Pentecoste (Pentecoste, Ceará, Brasil) no período de março a dezembro de 2004. Revista Ciência Agronômica, v.35, n.2, p.340-348, 2004.

ANA. Agência Nacional de Águas. Programa Nacional de Avaliação da Qualidade das Águas. Brasília: ANA, 2009.

APHA. American Public Health Association. Standart methods for the examination of water and wastewater. 21 ed. Washington: APHA, 2005.

ARANA, L. V.. Aquicultura e desenvolvimento sustentável: subsídios para a formulação de políticas de desenvolvimento da aqüicultura brasileira. Florianópolis: EDUFSC, 1999.

BARROS, R. V. G.; SOUZA, H. M. L.; SOUZA, C. A. Determinação do índice de qualidade da água (IQA) na subbacia do córrego André em Mirassol d'oeste, Mato Grosso. Revista Engenharia Ambiental, Espírito Santo do Pinhal, v.8, n.3, p.138 -153, 2011.

CETESB. Companhia de Tecnologia de Saneamento Ambiental. Relatório de qualidade das águas interiores do estado de São Paulo. São Paulo: CETESB, 2004

CETESB. Companhia de Tecnologia de Saneamento Ambiental. Relatório de qualidade das águas interiores do Estado de São Paulo. São Paulo: CETESB, 2006.

CETESB. Companhia de Tecnologia de Saneamento Ambiental. Relatório de qualidade das águas interiores do estado de São Paulo. São Paulo: CETESB, 2007.

CICIGLIANO, G. D.. Avaliação da qualidade da água em piscicultura com sistema de cultivo em tanques-rede no município de Santa Fé do Sul-SP. (Dissertação) Mestrado em Recursos Hídricos e Tecnologias Ambientais - Universidade Estadual Paulista, São Paulo, 2009.

CONAMA. Conselho Nacional do Meio Ambiente. Resolução n.357 de 17 de março de 2005. Brasília: CONAMA, 2005.

ESTEVES, F. A.. Fundamentos de Limnologia. 2 ed. Rio de janeiro: Interciência, 1998.

ESTEVES, F. A.. Fundamentos de Limnologia. 3 ed. Rio de janeiro: Interciência, 2011.
GOMES, D. F.. Estudo hidroquímico, isotópico e da dinâmica do nível estático das águas subterrâneas e superficiais da região de Limoeiro do Norte baixo Jaguaribe-Ceará. Tese (Doutorado em Engenharia Civil) - Universidade Federal do Ceará, Fortaleza, 2005.

GORAYEB, A.; GOMES, R. B.; ARAÚJO, L. F. P.; SOUZA, M. J. N.; ROSA, M. F.; FIGUEIREDO, M. C. B.. Aspectos ambientais e qualidade das águas superficiais na bacia hidrográfica do Rio Curu - Ceará - Brasil. Revista Holos Environment, v.7, n.2, 2007

GRASSHOFF, K.; EHRHARDT, M.; KREMLING, K.. Methods of seawater analysis. Hoboken: John Wiley \& Sons, 1983.

GURGEL, J. J. S.; FERNANDO, C. H.. Caracterização limnológica da grande bacia hidrográfica do Nordeste. In: CONGRESSO BRASILEIRO DE ENGENHARIA DE PESCA E CONGRESSO LATINO-AMERICANO DE ENGENHARIA DE PESCA. Anais. Recife: FAEP, 1999.

LAMPARELLI, M. C.. Grau de trofia em corpos d' água do estado de São Paulo: avaliação dos métodos de monitoramento. São Paulo: Tese (Doutorado em Ecologia Aplicada) - Universidade de São Paulo, São Paulo,2004.

MCNEELY, R. N.. Water quality sourcebook: a guide to water quality parameters. Otawa: Evironmental Canada, 1979.

OLIVEIRA, R. R. A.. Estudo da qualidade ambiental do reservatório pentecoste por meio do índice de estado trófico modificado. Dissertação (Mestrado em Desenvolvimento e Meio Ambiente) - Universidade Federal do Ceará, Fortaleza, 2009.

SIMÕES, F. S.; YABE, M. J. S.; MOREIRA, A. B.; BISINOTI, M. C.. Avaliação do efeito da piscicultura em sistemas aquáticos em Assis e Cândido Mota. Revista Química Nova, Londrina, v.30, n.8. pág.1835-1841, 2007.

SMIL, V.. Phosphorus in the environment: Natural Flows and Human Interferences. Annual Review of Environmet and Resources, p.53-88, 2000.

TOLEDO JUNIOR, A. P.. Informe preliminar sobre os estudos para a obtenção de um índice para a avaliação do estado trófico de reservatórios de regiões quentes tropicais. São Paulo: 1990. 
VALENTI, W. C.. A aquicultura brasileira é sustentável? SEMINÁRIO INTERNACIONAL DE AQUICULTURA, MARICULTURA E PESCA, 4. Anais. Florianópolis: AquaFair,2008.
VILAGINÈS, R.. Eau, environnement et santé publique: Introduction à l'hidrologie. 2 ed. Paris: Tec \& Doc Lavoisier, 2003.

VON SPERLING, E.. Avaliação do estado trófico de lagos e reservatórios tropicais. Revista BIO, n.3, p.68-76, 1994. 